\title{
DISTRIBUTIVE LEARNING IN INTRODUCTORY CHEMICAL ENGINEERING: UNIVERSITY STUDENTS' LEARNING, MOTIVATION, AND ATTITUDES USING A CD-ROM*
}

\author{
BARBARA A. GREENE \\ CONNIE DILLON \\ BILLY CRYNES \\ University of Oklahoma
}

\begin{abstract}
This article reports a study in which student performance and approaches to study in a CD-ROM version of a chemical engineering course were examined. The study consists of three phases. The purpose of phase 1 was to evaluate of the efficacy of CD-ROM for this content and student population. Therefore, we compared the performance of students who participated in a traditional classroom offering with those who participated in the CD-ROM version. The results supported the soundness of the CD-ROM based instruction. In phase 2, we interviewed students who were successful and less successful in the course to examine any differences in the strategies they used for learning the content. Differences consistent with a surface versus deep approach to studying were found. Prior to the third phase, the CD-ROM and approaches to learning instrument were modified and then a new group of students was examined to determine the factors that contribute to success in the CD-ROM version. Results showed that deep cognitive engagement and motivation, defined in terms of goals and self-efficacy, were significant predictors of success uses two indices of course performance. The results suggest that although technology provides opportunities for learners to learn in increasingly independent environments, educators need to prepare students to learn independently using newer electronic technologies.
\end{abstract}

*A version of the first study was presented at the EDEN Prague Research Workshop, March 2000 and at the 2001 annual meeting of the American Educational Research Association in Seattle, Washington. A version of the second study was presented at the 2002 annual meeting of the American Educational Research Association in New Orleans, Louisiana. 
Most higher education institutions are currently exploring ways to integrate technology into the curriculum. For many institutions, the primary motivation for turning to technology is to compete successfully for students who are interested in programs that offer courses that are conveniently delivered at a distance or via distributive learning environments. Distributive learning, which involves the use of technology to provide instruction in a manner that does not require the learner to be present with an instructor, can also change the nature of education so that it becomes less teacher-directed and more learner-centered. This type of change served as the impetus for the development of a CD-ROM for teaching an introductory Chemical Engineering course. The purpose of the three-phase study reported here was to examine learning, motivation, and attitudes toward learning shown by students using a CD-ROM to learn introductory material in Chemical Engineering. We concur with Navarro and Shoemaker's (2000) assertion that there is insufficient predictive research on distributive learning environments and with this work hoped to shed further light on the factors that predict success in distributive learning environments.

\section{BACKGROUND LITERATURE}

It can be said that cognitive psychology research has provided two robust findings with implications for instruction. First, cognitive engagement or cognitive strategy use during learning facilitates understanding and remembering new information (Greene \& Miller, 1996; Mayer, 1980; Nolen, 1988; Pintrich \& DeGroot, 1990; Zimmerman \& Martinez-Pons, 1990). By cognitive engagement or strategy use we mean the use of processes such as rehearsing, organizing, elaborating using existing knowledge, categorizing, constructing images, and problem solving. The implication is that the cognitive strategies that are appropriate for learning the material should be taught and their use encouraged during learning.

The second robust finding from cognitive psychology is that the ability to use or apply knowledge acquired is enhanced when the learner has a conceptual understanding of the content (Chi, Feltovich, \& Glaser, 1981; Mayer, 1989). By conceptual understanding we mean verbal knowledge of main concepts, principles, and theories that are central to the content domain. The implication being that instruction in a field should begin with the conceptual foundation of the field and subsequent courses build on that foundation. The lecture model for university-level instruction has traditionally focused on presenting students with the concepts, principles, and theories, but has not traditionally focused on teaching strategies for learning the key elements of the discipline. Although some students have learned to use active strategies either before or in college, many college students take a more passive or shallow approach, even though such an approach can hinder learning (Greene \& Miller, 1996; Nolen, 1988; Meece, Blumenfeld, \& Hoyle, 1988; Ravindran \& Greene, 2000). 
Researchers have attempted to identify learner factors that impact learning in distributive learning settings by focusing on either learner style variables or other learner psychological variables (Biner, Bink, Huffman, \& Dean, 1995; Coggins, 19889; Dille \& Mezack, 1991; Oxford, Young, Ito, \& Sumrall, 1993; Pugliese, 1994). Although the research provides some evidence that motivation, locus of control, and confidence are constructs that should be considered, it is difficult to draw any conclusions from this research. One major reason is that the instruments for measuring learner style variables are generally found to be problematic in terms of both reliability and validity (Geiger \& Boyle, 1992; Pittenger, 1993; Sewell, 1986).

We prefer to focus more on learner "approaches" than on learner "styles" or "types." Because types are "constant," learner differences must be addressed by changing the instruction rather than the nature of the learning. However, a more empowering and expedient method of addressing individual learner needs may be to identify effective approaches to learning and then help students acquire the metacognitive skills needed to adopt those approaches in settings where they have been found to lead to success (Dillon \& Greene, 2003). Given that distributive learning environments will require students to learn more independently (Richardson, 2000), a primary motivation for the work reported here was to identify the approaches to learning of successful students in an independent learning environment.

By approaches we mean the characteristics that learners bring to achievement settings that can vary from setting to setting, but define the stance they take toward learning in particular settings. Specifically, we define approaches in terms of the goals, self-efficacy, and cognitive engagement that students report in different achievement settings. Achievement goals characterize the different reasons students report for their efforts to learn in achievement situations (Greene \& Miller, 1996; Miller, Greene, Montalvo, Ravindran, \& Nicholls, 1996; Pintrich \& Garcia, 1991). Three types of goals have been found to be important for predicting cognitive engagement and achievement. Learning or mastery goals are when the student's focus is on gaining new knowledge and increasing competence. Performance or ego goals are when the student is focus on appearing competent and competing well. Future goals are when the student is focused on how the current achievement task is instrumental for success in some future endeavor. All three types are related to measures of perceived ability or self-efficacy (Miller et al., 1996).

Self-efficacy refers to the degree of confidence students possess in regard to their ability to successfully perform the current learning task (Kember \& Harper, 1987). The premise of self-efficacy theory is that confidence in one's ability to be successful in a specific learning situation is critical in order for sustained effort to be put forth to learn in that situation. There is considerable research that supports this theoretical assumption (Ames \& Archer, 1988; Bandura, 1986; Greene \& Miller, 1996; Miller et al., 1996; Pintrich \& Garcia, 1991; Zimmerman \& Martinez-Pons, 1990). 
Achievement goals and self-efficacy have been found to influence cognitive engagement or strategy use (Greene \& Miller, 1996; Miller et al., 1996; Pintrich \& Garcia, 1991). Cognitive engagement is the concrete, behavioral component of approaches to learning, while achievement goals and self-efficacy capture the more abstract aspect of motivation. Distinctions are often made between deep and shallow cognitive engagement (Greene \& Miller, 1996; Richardson, 2000). Deep cognitive engagement involves learning new information in metacognitive or thoughtful ways that elaborate on the new material and connect it with existing knowledge. Shallow cognitive engagement involves learning new information as isolated knowledge. Information processed in a shallow manner is maintained in nearly the original form as it was initially encountered. The practice of rote memorization is a common example of shallow cognitive engagement. In a distance education context, Kember and Harper (1987) found a relationship between surface approach to study and non-persisters in a correspondence study program.

The purpose of our phase 1 was to compare the performance of students in the distributive learning version of a chemical engineering course with performance of students in a traditional format before implementing a fully electronic version of the course. The goal was to ensure that the content would lend itself to independent learning with electronic media. In addition, phase 1 was a means of gathering information that could be used to improve the design of the CD-ROM-based instruction. In phase 1 we also examined differences in motivation and attitudes toward learning between students in the traditional and the CD-ROM sections. Phase 2 was conducted to examine the strategies used by students who were successful versus less successful. The intent was to determine the approaches used by successful students to ensure that the design of the CD-ROM instruction supported those approaches. Finally, phase 3 was conducted with students who were all using the CD-ROM to examine their approaches to learning and to identify factors that contributed to success in the distributed learning setting. In addition, phase 3 provided information about the improvements made based upon the formative data collected in phase 1.

\section{PHASE 1}

\section{Method}

\section{Participants}

The sample consisted of 73 student volunteers enrolled in an introductory course on chemical engineering fundamentals. There were 26 students in the distributed section and 47 students in the traditional section. Approximately 60 percent of the students were male and the majority was traditional students between the ages of 18 and 21. There were 3 freshman, 37 sophomores, 29 juniors, 2 seniors, and 2 who declined to report. There were 62 students who reported 
English being their first language, 8 who reported English as not being their first language, and 3 who declined to report.

\section{Setting and Instructional Methods}

The course is a prerequisite for full admission into the chemical engineering program. One section of the course was offered in the traditional format that met for three 50-minute periods a week and involved lecture, question and answer time during class, homework, and a textbook. The other section was offered using a distributed learning format with an emphasis on self-guidance, electronic communication, and learning via the use of a specially prepared CD-ROM. In the distributed version, the students were required to meet only once a week, although the remaining two class periods were always available for tutoring or examinations for mastery of modules. The CD-ROM was designed with embedded interactivity to provide immediate feedback and to emphasize critical concepts. The structure of each module was driven by examples, followed by practice problems, and then a test over mastery of the module content.

\section{Instruments}

The Initial Learning Approaches instrument was designed to assess the following constructs: 1) goals, including learning, performance, and future goals; 2) selfefficacy for success in the class, for background content considered prerequisite, and in the electronic delivery system (for those in the distributed section); and 3 ) study strategies. The goal, self-efficacy, and cognitive engagement items were adapted from an instrument developed and validated by Miller et al. (1996).

The Attitudes Toward the Course instrument was developed for this study and used at the end of the semester, but before the final exam was taken. This instrument addressed perceived helpfulness of different aspects of the course, perceived achievement of the course objectives specified in the syllabus, attitudes toward the instructor, and attitudes toward the course. In addition, students were asked to identify some study strategy practices relating to reading the material and working practice problems.

The final exam, which was the same for both sections, was the primary achievement measure. The test consisted of 15 single-response items (no work to be shown) worth 7 points each and five items worth 10 to 30 points that required application and analysis of course content. We also examined percentage of course points as a second achievement measure.

Design

An exploratory causal comparative design was used to compare the two groups of students on their approaches to learning, attitudes toward the class, and their achievement. The variables to be compared were chosen so that a number of different characteristics could be examined to help explain students' approaches, 
attitudes, and achievement across the two instructional methods. Additionally, it was thought that these were characteristics that would provide information that could be used to improve on the design of the CD-ROM.

\section{Procedures}

On the first day of class the instructor gave a pretest measuring background knowledge of relevant chemistry and physics concepts. At that time the instructor also told students they could switch sections depending on their choice of course design. During the first week of the semester, students were invited to participate in the study and informed consent forms were signed. During the week prior to the midterm, the Initial Learning Approaches instrument was completed at the beginning of a regular class session. During the last week of classes, the Attitudes Toward the Course instrument was completed at the start of a class session.

\section{Results}

Cronbach alpha reliability coefficients were computed for each of the subscales measured by the two instruments. Given that internal consistency is a requirement for validity, subscales not found to be reliable were not included in subsequent analyses. The coefficients for the three goal and the general self-efficacy subscales were sufficiently high (ranged from .82 to .92) to provide solid evidence for the internal consistency of the scales. These values were also consistent with the values found in previous research using these items and subscales (Greene \& Miller, 1996; Miller et al., 1996).

The shallow strategy items did not meet the minimum criterion of coefficient alpha .50 (Popham, 1990). After examining item intercorrelations, we found that the combination of the deep and shallow items, without two items, was more reliable than the deep (.65) or shallow (.45), so we used the combined strategy subscale (alpha $=.82)$ and called it cognitive engagement.

We created four subscales from the Attitudes Toward the Course instrument, all of which had acceptable coefficient alphas. The scale for perceptions of helpfulness of different aspects of the course had a coefficient alpha of .61. The scale for whether or not students thought they learned the course objectives had a coefficient alpha of .84. A scale for whether students reported reading all the instructional materials was created was by combining two separate two-item scales created for each section (based on different items). The coefficient alphas for the traditional and distributed groups were .89 and .71 , respectively. The fourth scale was based on items asking whether students read material more than once or re-worked problems and had a coefficient alpha of .66.

Means and other descriptive statistics are shown in Table 1. Mean differences were explored using independent $t$ tests when differences greater than .30 were observed. Given that we had two relatively small samples, we did not adjust our alpha to account for conducting multiple tests on the same samples since we 
Table 1. Means, Standard Deviations for the Instrument Subscales Used in Phase 1 Analyses

\begin{tabular}{|c|c|c|c|c|c|c|}
\hline \multirow[b]{2}{*}{ Subscales } & \multicolumn{3}{|c|}{ Traditional } & \multicolumn{3}{|c|}{ Distributed } \\
\hline & Mean & $N$ & $S D$ & Mean & $N$ & $S D$ \\
\hline Pretest & 55.26 & 42 & 13.50 & 56.05 & 26 & 14.05 \\
\hline Final exam & 143.15 & 47 & 28.98 & 128.54 & 26 & 34.29 \\
\hline Grade \% & 74.26 & 47 & 12.43 & 74.20 & 26 & 14.83 \\
\hline Learning goals & 5.11 & 39 & .90 & 4.88 & 23 & .92 \\
\hline Performance goals & 2.67 & 40 & 1.47 & 2.38 & 21 & .86 \\
\hline Future goals & 5.34 & 40 & .825 & 5.03 & 23 & .99 \\
\hline General self-efficacy & 4.99 & 40 & .81 & 4.74 & 22 & .54 \\
\hline Background self-efficacy & 5.30 & 43 & .71 & $4.91^{a}$ & 25 & .60 \\
\hline $\begin{array}{l}\text { Self-efficacy for } \\
\text { electronic mode }\end{array}$ & & & & 5.04 & 22 & .55 \\
\hline Cognitive engagement & 4.15 & 42 & .85 & 3.89 & 25 & .76 \\
\hline Effort & 3.28 & 43 & .83 & 3.12 & 24 & 1.03 \\
\hline Helpful & 4.10 & 34 & 1.23 & $4.78^{b}$ & 23 & .62 \\
\hline Learned objectives & 4.95 & 38 & 1.00 & 5.09 & 23 & .61 \\
\hline Read all & 2.79 & 39 & .83 & 2.85 & 23 & .66 \\
\hline $\begin{array}{l}\text { Read/did more } \\
\text { than once }\end{array}$ & 1.87 & 39 & .83 & $2.48^{b}$ & 23 & .73 \\
\hline Positive attitude profile & 5.09 & 38 & .95 & 4.60 & 23 & .85 \\
\hline
\end{tabular}

Note: Effort was a single item on a 5-point scale; Read all; Read/did more than once were on for point scales, all other survey items were on a 6-point scale.

${ }^{a}$ Signifies that the $t$-test for differences between means is significant at the 0.05 level. ${ }^{b}$ Signifies that the $t$-test for differences between means is significant at the 0.01 level. 
believed that we were more likely to fail to find statistical significance, due to the low power associated with small samples. However, we recognize that caution must be used when interpreting such exploratory results.

Three statistically significant differences (using $p<.05$ ) between the traditional and the distributed sections were found among the seven tests we conducted. The distributed group had lower self-efficacy for background knowledge $(t(66)=2.23$, $p=.029$ ), but had higher mean ratings on the perceived helpfulness of aspects of the course format $(t(55)=-2.75, p=.008)$ and had higher means on reviewing course materials more than once $(t(60)=-2.89, p=.005)$. The two groups did not differ on the pretest. The traditional group had a higher mean on the final exam, but the 15 point difference did not reach statistical significance $(t(71)=1.93, p=.057)$.

The two self-efficacy variables were both positively correlated with the final exam ( $r$ for general self-efficacy $=.32$ and for background knowledge selfefficacy $=.22$ ). Correlations among Attitudes Toward the Course subscales with achievement and effort showed that two attitude variables were related to achievement. Students who scored high on thinking that they learned the course objectives did in fact do better on the final exam $(r=.35)$. However, students who scored high on the variable capturing whether or not they reread problems scored lower on the final exam $(r=-.46)$.

Finally, the Attitudes Toward the Course data revealed several problems with the CD-ROM. For example, students thought animation and pop-ups were overused. Plus, a few navigation problems were noted. More importantly, though, some of the feedback routines indicated answers were wrong when they only varied in terms of differences in rounding off numbers. These problems were addressed in the modified version of the CD-ROM used in phase 3 .

\section{PHASE 2}

\section{Method}

Participants and Design

Successful and unsuccessful students from both the traditional and distributed groups in the same Chemical Engineering course that was studied in phase 1 were interviewed at the beginning of the following semester. The instructor identified 20 students that represented "typical" cases (five from each group). Of these, 11 students agreed to participate. Of the 11, there were four students who earned a grade of D or F (the unsuccessful group) and seven who earned a grade of A or B (the successful group). The interview design was chosen so that the approaches used by students could be explained in their own words.

Instruments

An interview schedule with seven questions was developed for this phase. Students were asked questions that related to their choice of major and section. 
They were asked to describe what they did when they studied for this course. More specifically, the students were asked to describe their approaches to studying, what strategies they used when they had trouble completing the problems, and how they studied for exams. Probing questions were asked in addition to the seven initial questions in order to get participants to explain their answers.

\section{Procedures}

The interviewer met students in the cafeteria of the student union at an agreed upon time. Each interview was audio taped and lasted about 30 minutes. The interview data were transcribed and then analyzed by two researchers independently to identify common themes. In the preliminary analysis, successful and less successful students were not identified. After identifying themes, the interviews were grouped according to success and this analysis was repeated.

\section{Results}

The findings from the interview data are consistent with the literature with respect to differences in approaches to problem solving between experts and novices (Chi, Glaser, \& Farr, 1998). Although there is some evidence that the less successful students also made less effort, this is certainly not the pattern. Two students said they "blew off" the first part of the course, because the content was relatively easy. They described skimming the problems, rather than working through them. One student recognized this early overconfidence was a mistake and attempted to make adjustments by increasing the level of effort, using strategies such as contacting the professor, and re-writing the problems step by step. The less successful students studied for tests by reviewing the modules, because "the answers were almost the same." But they found the tests difficult. "I thought I understood it [before I took the test] but couldn't do it on the test" ... "there might be a number at a different place ... they'd change something." Another approach these students reported using was working through the problems backwards. "I did the practice problems by working backwards. I'd throw in an answer and it would say 'incorrect' and then it would tell me how I was supposed to do it. I didn't try to work the problems before, I'd just see what 'they' did." The instructor reported emphasizing the "steps" associated with solving problems and all students stated that they knew these steps and applied the steps when studying. "I could identify the steps, it was just actually working and coming up with the answer that messed me up." In other words, the less successful students knew "what to do" but did not seem to know "why." They knew the steps but did not understand the concepts. When stumped, these students reported reviewing the problem, "going over and over it" to see if they could understand it. If that failed, they generally asked the professor or a friend for help.

Consistent with Richardson (2000), the more successful students also reported using surface approaches in that they, too, described skimming the materials, 
writing down the problems step-by-step, and when really stuck, working through the problems backwards. However, they seemed to use these strategies to understand the concept, rather than simply to work through the problems. "I just skimmed though the sample problems to get the general idea," is a comment one student made to reflect this idea. The successful students also described approaching the problems step by step. However, they talked about looking beyond the steps. For instance, one student said “. . . for each step I would write down the assumptions . . . and pick out the important points and make sure I understood those." Another student said "I'd try to combine the problems into concepts." Several of these students described using "organizing" strategies. One student organized their notes. Another described using organizing strategies as the problems became more difficult, ". . . organization was a real problem, like breaking down the big pictures to little bitsy things where you could start." These successful students actually used terms like concepts, general or basic idea. Many of their statements represented a rather sophisticated understanding of how they best learned. For instance, "writing helps me remember ...."; "I'd combine the problem into concepts"; "[I write because] I can't do things visually very well"; and "I'd scan the material - a little deeper than scanning." Another student relied upon looking at different examples because that student understood that "theory doesn't make sense until I see examples." As they identified difficulty with one approach they would try a different approach.

Both the successful and less successful students were motivated and both groups did the work. However, there are some important differences between the successful and less successful students. The less successful students focused upon memorizing and applying what they had memorized. The successful students focused upon understanding the concepts. The less successful students skipped the easier parts of the work and in doing so failed to take advantage of the opportunity to activate prior learning. While the successful students reported skimming the easier parts, they were also looking for areas that they failed to understand. The successful students talked about "how they learned" and the less successful students did not. Both groups used surface strategies, but the successful students also used deep strategies and appeared to be aware of the difference between these approaches to learning. They seem to be able to use this awareness to make decisions about how to approach learning whereas the less successful students continued to rely upon strategies that were not working.

\section{DISCUSSION: PHASES 1 AND 2}

Unlike Navarro and Shoemaker (2000), we found no statistically significant differences in performance between students in the CD-ROM and traditional sections. We did, however, find that students in the distributed group were different from the traditional group students in a way that was detrimental to achievement. The distributed group had lower self-efficacy for the required 
background knowledge when high self-efficacy for such knowledge predicted high achievement in this context. Additionally, the distributed group seemed to engage in more processing of the instructional materials than the traditional group, but the relationship with such processing and achievement was negative, suggesting that the extra processing was not what was needed for success in this context. The instructor realized that he might have inadvertently encouraged students who were less prepared for the course into the CD-ROM section by suggesting that he would be more lenient since it was a formative evaluation. Given this information and the other results, we think the CD-ROM is a viable instructional tool in this setting was valid.

The analysis of the interview data showed a tendency for less successful students to use more superficial than deep processes. The less successful students in the electronic group had a tendency to not work the problems. This was especially true in the beginning when the material and problems were easy. Several students noted that, in retrospect, they had made a mistake by not doing the early problems because once the problems got harder they were at a loss for how to approach them. When they did attempt to solve problems in the modules they tried to remember specific steps to specific problems or used a "working backward" heuristic. In this way, they were more focused on sequential approaches to learning. These approaches did not foster deep learning of the underlying principles necessary for solving new problems, nor did they encourage the learning of more useful strategies for successful solving problems.

The more successful learners tried to figure out what the main concepts were for each problem before attempting to solve a problem. Research has shown that students who are able to use relevant prior knowledge or schemata specific to problems tend to be more successful than students who are not able to use such knowledge (Robins \& Mayer, 1993). Additionally, as Anderson (2000) pointed out, there is considerable evidence from research on expert versus novice problem solving that consistently shows that experts understand problems in their domain of expertise in terms of the main concept or underlying principle before they attempt to solve problems. In other words, our more successful students engaged in problem solving in ways that were more expert-like than did our less-successful students. Once the more successful students figured out the main concept, they knew how to solve the problem, so they sometimes did not work it out. However, they were generally more likely to report focusing on solving the example problems than were the less-successful students.

The other factor that was obviously different with the successful students was that they demonstrated a high degree of metacognition or awareness of their own learning. Research supports the importance of metacognition for successful learning (Garner \& Alexander, 1989). Our successful learners were much more likely to describe what works best for them in a course such as this one and they often described how they were checking their understanding through out the course. 
Importantly, the approaches noted by the successful students were consistent with what is encouraged in the instructional method of the CD-ROM. For example, in the CD-ROM the general problem solving procedure begins with a prompt to identify the major concept. This is consistent with the successful students noting that they first identified the major concept associated with a problem. Additionally, the emphasis on practice with solving problems should increase metacognition (since students are continually working problems that they either can or cannot solve and getting feedback). The interview results suggested that metacognition is another characteristic shown by the successful students and not by the less successful students.

\section{PHASE 3}

\section{Method}

Design

Overall, the results from phases 1 and 2 indicated that the distributed CD-ROM was a viable method for instruction with this course. In phase 3, our focus shifted from the comparison of two different treatments to an examination of what contributes to success in a course which emphases self-guidance and independent study. This study used correlational techniques, including multiple regression, to examine the contributions of the different variables to the prediction of both strategy use and achievement.

\section{Participants}

Of the 87 students enrolled in the Chemical Engineering course, 66 agreed to participate in the study. Over one-half of the students were sophomores (56.1 percent) and 30.2 percent were juniors. Over three-fourths ( 77 percent) indicated that English was their first language.

\section{Setting and Instructional Methods}

The same Chemical Engineering course that was studied in phases 1 and 2 was again the focus. This time, however, there was no traditional format; all students had to learn the material via the CD-ROM. The CD-ROM had been modified to address concerns students noted in the first study. These modifications were not substantive.

Instruments

A demographic survey was used to collect data on demographic and relevant educational experience. The pre-test was again used to measure entering knowledge on key concepts related to the course. 
The Approaches to Learning survey used in phase 1 was used again with only slight modifications. It assessed the following constructs: 1) goals, including learning, performance, and future goals; and 2) self-efficacy for success in the class, for background content considered prerequisites, and in the delivery system; and cognitive engagement. This survey was administered midway through the course, just before the midterm exam. The Attitudes Toward the Course instrument was administered at the end of the semester, before the final exam was given. We used two achievement variables, percentage of course points earned and score on the comprehensive final exam.

\section{Procedure}

All instruments were completed at the beginning of regular class session. The inform consent form, demographic survey, and pretest were administered at the beginning of the course. As in phase 1, the week before the midterm exam, student completed the Initial Learning Approaches instrument. During the last week of classes, the Attitudes Toward the Course instrument was completed.

\section{Results and Discussion}

The data were first summarized in terms of descriptive statistics and then a series of analyses were conducted. The data for the achievement, motivation, cognitive engagement, and attitudes toward the course variables are summarized in Table 2. The means on the goal variables, the self-efficacy variable and the confidence variables suggest that student motivation related to the class was generally positive. The means on the deep cognitive engagement and shallow processing variables show that both types of processing were used. It should be noted, though, that the measure of shallow processing was not sufficiently reliable and was, therefore, not included in the regression analyses.

In Table 3 the correlations of the approaches to learning variables with pretest and the two achievement measures are reported. From the table we can see that among the motivation variables, learning goals, future goals, and self-efficacy have the highest correlations with final exam scores and percentage of course points. The variables asking about confidence in the mathematics and chemistry prerequisites were both correlated with percentage of course points. The variable measuring degree of deep cognitive engagement was correlated with percentage of course points.

There were four items from the Attitudes instrument that were correlated with the achievement measures. There was a positive correlation between the belief that students learned problem solving strategies and the final exam $(r=.258, p=.04)$ and the course grade $(r=.264, p=.038)$ variables. The highest correlations were positive correlations between the belief that students learned to use material and energy balance elements in problem solving and the final exam $(r=.324, p=.014)$ and course grade $(r=.396, p=.003)$ variables. The item about whether a student 
Table 2. Descriptive Statistics for the Instrument Subscales Used in Phase 3

\begin{tabular}{|c|c|c|c|c|c|c|}
\hline Variable & Mean & $S D$ & $N$ & Minimum & Maximum & $\begin{array}{l}\text { Reliability } \\
\text { coefficient }\end{array}$ \\
\hline Pretest & 67.60 & 26.13 & 55 & 13.00 & 137.00 & \\
\hline Final exam & 137.34 & 32.37 & 53 & 25.00 & 182.00 & \\
\hline Percent of course points & 75.00 & 13.00 & 53 & 33.00 & 93.00 & \\
\hline Learning goal & 4.98 & .65 & 62 & 2.67 & 6.00 & .50 \\
\hline Future goal & 5.19 & .66 & 60 & 3.67 & 6.00 & .80 \\
\hline Performance goal & 2.77 & 1.33 & 62 & 1.00 & 5.00 & .83 \\
\hline Future goals in technology & 4.48 & 1.03 & 62 & 1.50 & 6.00 & .93 \\
\hline Self-efficacy & 4.50 & .91 & 59 & 2.00 & 6.00 & .83 \\
\hline $\begin{array}{l}\text { Self-efficacy for background } \\
\text { knowledge }\end{array}$ & 5.08 & .82 & 62 & 2.33 & 6.00 & .77 \\
\hline $\begin{array}{l}\text { Self-efficacy for use of } \\
\text { technology for learning }\end{array}$ & 4.96 & .87 & 61 & 1.50 & 6.00 & .64 \\
\hline Deep cognitive engagement & 4.28 & .83 & 61 & 2.17 & 5.83 & .80 \\
\hline Shallow & 4.54 & .78 & 62 & 2.67 & 6.00 & .49 \\
\hline CD-ROM helpful & 4.48 & 1.18 & 48 & 1.00 & 6.00 & \\
\hline Learned problem solving & 4.86 & 1.04 & 49 & 2.00 & 6.00 & \\
\hline $\begin{array}{l}\text { Learned to use material } \\
\& \text { energy balance elements }\end{array}$ & 5.00 & 1.00 & 49 & 3.00 & 6.00 & \\
\hline Read all the CD-ROMS & 3.67 & .53 & 48 & 2.00 & 4.00 & \\
\hline Read more than once & 3.15 & .77 & 48 & 2.00 & 4.00 & \\
\hline
\end{tabular}

read all the CD-ROM modules was positively correlated with course grade $(r=.326, p=.014)$ and with final exam $(r=.243, p=.054)$, though the latter correlation was marginally significant. Also marginally significant was a positive correlation between the item asking about whether the students reviewed the modules more than once $(r=.284, p=.05)$. Since the attitude questions were single items rather than variables, they were omitted from the regression analyses. 
Table 3. Study 2 Correlations between Motivation and Style Variables with Pretest and Two Achievement Variables

\begin{tabular}{|c|c|c|c|}
\hline Variables & Pretest & $\begin{array}{l}\text { Final } \\
\text { exam }\end{array}$ & $\begin{array}{c}\text { Percent } \\
\text { course points }\end{array}$ \\
\hline Pretest & 1.000 & & \\
\hline Final exam & $.366^{\star \star}$ & & \\
\hline Percent of course points & $.247^{\star}$ & & \\
\hline Learning goal & -.099 & $.279^{*}$ & $.350 * *$ \\
\hline Future goal & -.010 & $.247^{\star}$ & $.371^{\star \star}$ \\
\hline Performance goal & -.152 & .102 & .021 \\
\hline Future goals in technology & .206 & .146 & -.010 \\
\hline Self-efficacy & $.267^{\star}$ & $.418^{\star \star}$ & $.361^{* *}$ \\
\hline Self-efficacy for background knowledge & .11 & .19 & $.28^{*}$ \\
\hline Self-efficacy for electronic medium & $.29^{*}$ & .14 & .11 \\
\hline Deep cognitive engagement & .031 & .216 & $.320^{*}$ \\
\hline Shallow & -.070 & $.248^{*}$ & $.286^{*}$ \\
\hline
\end{tabular}

Two regression analyses were conducted to examine the extent to which the deep cognitive engagement variable and the motivation variables might predict final exam scores and percentage of course points earned after variance accounted for by the pretest scores was partialled out. In the prediction of final exam scores, after pretest scores explained 10.9 percent of the variance, deep cognitive engagement predicted a unique and statistically significant 11.8 percent of the variance, and the motivation variables predicted another statistically significant 9.4 percent of the variance. The overall analysis explained 32 percent of variance $(F(5,39)=3.70, p=.008)$.

In the prediction of percentage of course points, after pretest scores explained 5.2 percent of the variance, deep cognitive engagement predicted a unique and statistically significant 12.1 percent of the variance, the motivation variables predicted another statistically significant 15.2 percent of the variance. The overall analysis explained 32.6 percent of variance $(F(5,39)=3.765, p=.007)$. 


\section{GENERAL CONCLUSIONS AND SIGNIFICANCE OF FINDINGS}

The findings from phase 1 suggest that the CD-ROM can be an effective instructional tool for teaching Chemical Engineering. From phase 2 we can conclude that to be successful, students need to use the features of the instruction as they were designed. In particular, working through the problems from beginning to end. From phase 3 we know that to be successful it helps when students have future goals, high self-efficacy, and use deep cognitive engagement when studying or working with the material.

We think the findings from this three-phase study give us information that we can use to modify the instruction to help learners be more successful when learning in a CD-ROM course such as the one studied here. First, we would include in the general instructions a rationale for why students should work the problems rather than just read or even skim them. Second, we would have prompts throughout the instructional modules that would remind students to reflect on what is clear and not clear to them, what is difficult and easy. These prompts would also recommend ways for students to get their confusions cleared up or the their questions answered. These suggestions are consistent with literature on metacognition (Garner \& Alexander, 1989). Finally, the practice problems throughout the modules would ask students to first identify the main concept or principle behind each problem before they attempt to work the problem. If students were unable to identify the main principle, then a pop up explanation would be provided that included how students might recognize another example of such a problem. The next set of problems would be another example of a problem based on that same main principle, followed by a problem not based on that main principle. Future research should validate these instructional suggestions.

The ultimate goal of our research is help learners be more successful. We hope that the use of distributed learning technologies in education will help more learners to be successful rather than increasing the gap between successful and unsuccessful learners. Our findings suggest that the variables most important to student success are self-efficacy, future goals, learning goals, and metacognition. Although we are not discounting "ability," we think that the best way to meet individual learner needs is not by designing the instruction based upon some assessment of an individual learner's "style" or "trait." Instruction and feedback should be designed to encourage domain specific self-efficacy. There are occasions in which feedback can create more anxiety than confidence; this might be especially true when face to face interaction is not available. Future research should be examine the effects of electronic feedback to ensure that it is not undermining student self-efficacy. Our research suggests that individualized instruction should individualized in terms of the learner's own goals, rather than in terms of what the learner prefers. Finally, we should design instruction to help students modify their approaches to learning rather than modifying the instruction to 
accommodate individual learning approaches. Instruction should help students learn how to learn, rather than allow students to continue to use unsuccessful approaches.

Future research should focus upon identifying learners who are at risk of failure but who have the potential to succeed. We are currently working on a large $N$ study that will help us assess the predictive validity of the approaches instrument. Our research suggests that using the approaches to learning data in conjunction with a measure of entering knowledge will help identify learners who need guidance. In addition, future research should examine the effectiveness of the interventions that target these students.

In conclusion, we think that this research suggests some approaches to modifying CD-ROM based instruction of this nature. Instruction should be augmented so that it helps students develop skills for applying the concepts that they are learning. Additionally, the instruction should encourage more metacognitive processing throughout the modules. The growth of distributed learning in education will continue to place more responsibility for learning upon the learner. This is desirable, of course. However, we must work to make sure that all learners who have the potential to be successful are ultimately successful. In other words, when designing more independent learning environments, we must also include strategies to help students learn how to become more independent learners.

\section{REFERENCES}

Anderson, J. R. (2000). Cognitive psychology and its implications (5th ed.). New York: Freeman.

Ames, C., \& Archer, J. (1988). Achievement goals in the classroom: Students' learning strategies and motivation processes. Journal of Educational Psychology, 80, 260-267.

Bandura, A. (1986). Social foundations of thought and action: A social cognitive theory. Englewood Cliffs, NJ: Prentice Hall.

Biner, P. M., Bink, M. L., Huffman, M. L., \& Dean, R. S. (1995). Personality characteristics differentiating and predicting the achievement of televised-course students and traditional-course students. The American Journal of Distance Education, 9(2), 46-60.

Chi, M. T. H., Feltovich, P. J., \& Glaser, R. (1981). Categorization and representation of physics problems by expert and novices. Cognitive Science, 5, 121-152.

Chi, M. T. H., Glaser, R., \& Farr, P. J. (1993). The nature of expertise. Hillsdale, NJ: Erlbaum.

Coggins, C. C. (1988). Preferred learning styles and their impact on completion of external degree programs. The American Journal of Distance Education, 2(1), 25-37.

Dille, B., \& Mezack, M. (1991). Identifying predictors of high risk among community college telecourse students. The American Journal of Distance Education, 5(1), 24-35.

Dillon, C., \& Greene, B. A. (2003). Learner differences in distance education: Finding differences that matter, in Handbook of distance learning. Mahwah, NJ: Erlbaum.

Garner, R., \& Alexander, P. A. (1989). Metacognition: Answered and unanswered questions. Educational Psychologist, 24, 143-158. 
Geiger, M. A., \& Boyle, E. J. (1992). A factor analysis of Kolb's Revised Learning Style Inventory, Educational and Psychological Measurement, 52(3), 753-759.

Greene, B. A., DeBacker, T. K., Ravindran, B., \& Krows, A. J. (1999). Goals, values, and beliefs as predictors of achievement and effort in high school mathematics classes. Sex Roles, 40(5), 421-458.

Greene, B. A., \& Miller, R. B. (1996). Influences on course performance: Goals, perceived ability, and self-regulation. Contemporary Educational Psychology, 21, $181-192$.

Kember, D., \& Harper, G. (1987). Implications for instruction arising from the relationship between approaches to studying and academic outcomes. Instructional Science, 16, 35-46.

Mayer, R. E. (1980). Elaboration techniques that increase the meaningfulness of technical text: An experimental test of a learning strategy hypothesis. Journal of Educational Psychology, 72, 770-784.

Mayer, R. E. (1989). Models for understanding. Review of Educational Research, 59, 43-64.

Meece, J. L., Blumenfeld, P. C., \& Hoyle, R. H. (1988). Students' goal orientations and cognitive engagement in classroom activities. Journal of Educational Psychology, $80,514-523$.

Miller, R. B., Greene, B. A., Montalvo, G. P., Ravindran, B., \& Nicholls, D. (1996). Engagement in academic work: The role of learning goals, future consequences, pleasing others, and perceived ability. Contemporary Educational Psychology, 21, 388-442.

Navarro, P., \& Shoemaker, J. (2000). Performance and perceptions of distance learners in cyberspace. American Journal of Distance Education, 14(2).

Nolen, S. B. (1988). Reasons for studying: Motivational orientations and study strategies. Cognition and Instruction, 5, 269-287.

Oxford, R., Young, P., Ito, S., \& Sumrall, M. (1993). Factors affecting achievement in a satellite delivered Japanese language program. The American Journal of Distance Education, 7(1), 11-25.

Pintrich, P. R., \& DeGroot, E. V. (1990). Motivational and self-regulated learning components of classroom academic performance. Journal of Educational Psychology, $82,33-40$.

Pintrich, P. R., \& Garcia, T. (1991). Student goal orientation and self-regulation in the college classroom. In M. Maehr \& P. R. Pintrich (Eds.), Advances in motivation and achievement: Goals and self-regulatory processes (Vol. 7, pp. 271-402). Greenwich, CT: JAI Press.

Pittenger, D. J. (1993). The utility of the Myers-Briggs Type Indicator, Review of Educational Research, 63(4), 467-488.

Popham, J. W. (1990). Modern educational measurement: A practitioner's perspective (2nd ed.). Englewood Cliffs, NJ: Prentice-Hall.

Pugliese, R. R. (1994). Telecourse persistence and psychological variables. The American Journal of Distance Education, 8(3), 22-39.

Ravindran, B., \& Greene, B. A. (2000). The role of goals, beliefs and cognitive engagement in the prediction of preservice teachers' knowledge integration. Paper presented at the Annual Meeting of the American Educational Research.

Richardson, J. T. E. (2000). Researching student learning. Buckingham, UK: The Society for Research into Higher Education and Open University Press. 
Robins, S., \& Mayer, R. E. (1993). Schema training in analogical reasoning. Journal of Educational Psychology, 85, 529-538.

Sewell, T. J. (1986). The measurement of learning style: A critique of four assessment tools. Green Bay, WI: Assessment Center, University of Wisconsin. (ERIC Document Reproduction Service No. ED 267-247.)

Zimmerman, B. J., \& Martinez-Pons, M. (1990). Student differences in self-regulated learning: Relating grade, sex, and giftedness to self-efficacy and strategy use. Journal of Educational Psychology, 82, 51-59.

Direct reprint requests to:

Dr. Barbara Greene

Department of Educational Psychology

820 Van Vleet Oval

University of Oklahoma

Norman, OK 73019

e-mail: bgreene@ou.edu 